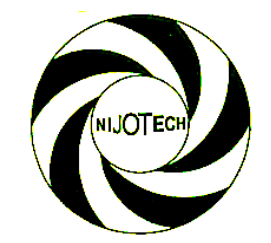

Nigerian Journal of Technology (NIJOTECH)

Vol. 39, No. 3, July 2020, pp. 932 - 941

Copyright@ Faculty of Engineering, University of Nigeria, Nsukka

Print ISSN: 0331-8443, Electronic ISSN: 2467-8821

www.nijotech.com

http://dx.doi.org/10.4314/njt.v39i3.36

\title{
EFFECTS OF MICROWAVE POWER AND SLICE THICKNESS ON FIBER AND ASH CONTENTS OF DRIED SWEET POTATO (IPOMOEA BATATA)
}

\author{
C. O. Nwajinka',*, E. O. Okonjo ${ }^{2}$, D. O. Amaefule ${ }^{3}$ and D. C. Okpala ${ }^{4}$

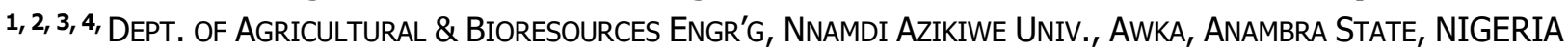 \\ Email addresses: ${ }^{1}$ oc.nwajinka@unizik.edu.ng, 2 okonjoleonard14@gmail.com, \\ 3da.amaefule@unizik.edu.ng, ${ }^{4}$ nonsookpala28@yahoo.com
}

\begin{abstract}
Investigation of microwave drying of sweet potato slices was conducted at microwave oven power settings of 90, 100, 120 Watts and slice thicknesses of $3 \mathrm{~mm}, 4 \mathrm{~mm}$ and $6 \mathrm{~mm}$ using Fourier models and response surface methods. The slice samples dried from initial moisture content of $70.71 g_{\text {water }} / g_{\text {dry matter }}$ to $12.7 g_{\text {water }} / g_{\text {dry matter }}$ final (equilibrium) moisture content in the microwave oven. Fourier models adequately fitted the drying data with the following values of the fit parameters: $M B E=0.00002943$ to $0.000645, R^{2}=0.9987$ to $1, R M S E=0.00384$ to 0.01692 . Effective moisture diffusion coefficient $\left(D_{e}\right)$ of the samples ranged from $1.0822 \times 10^{-3} \mathrm{~m}^{2} / \mathrm{s}$ to $8.3812 \times 10^{-3} \mathrm{~m}^{2} / \mathrm{s}$. Analysis of Variance (ANOVA) was used to analyze the effect of drying conditions on the samples parameters at $95 \%(p<0.05)$. The results showed that slice thickness and microwave power have significant effects on the ash and fiber contents of the dried potato samples. At the microwave power of $90 \mathrm{~W}$ and slice thickness of $4 \mathrm{~mm}$ the values of Fiber and Ash retained in the dried sweet potato samples were optimal at $4.30 \%$ and $2.50 \%$ respectively, after drying for 390 minutes to an average moisture content of $14.2 \mathrm{~g}_{\mathrm{H} 2 \mathrm{O}} / \mathrm{g}_{\mathrm{dm}}$. Optimized equations for predicting the percent ash and fiber contents at combined factors of microwave power and slice thickness were developed using Response Surface Methodology (RSM) at 95\% confidence bound. The coefficients of determination $\left(R^{2}\right)$ for the models are 0.7333 and 0.9655 for fiber and ash respectively. These are indications that the models can be used to predict the two food components of microwave dried potato slices.
\end{abstract}

Keywords: RSM, Fourier Model, Microwave, Sweet Potato, Ash, Fiber

\section{INTRODUCTION}

Microwave drying is an efficient method of postharvest processing of agricultural products due to its associated time efficiency, low energy consumption and high product quality. Compared to convective drying, microwave drying can be advantageous due to its volumetric heating and reduced processing time [1]. The applicability of this process to a wide range of foods, with diverse characteristics render this operation a prominent position in the food industry [2]. Sweet Potato (Ipomoea batatas), is a dicotyledonous plant that belongs to Convolvulaceae family. It is an important and valuable staple crop worldwide [3]. Approximately 106 million tonnes of sweet potato was produced across the globe at the rate of about 13.2 tonnes per hectares in 2010 [4]. Nigeria ranks second in Africa after Uganda with the production figure of 2,883,408 tones which showed an increase over the years. Generally, sweet potato (SP) has continued to be popular crop among farmers in Nigeria because it generates income for smallholder farmers. Its nutritional and health benefits together with a long shelf life and ease of food preparation makes sweet potato a highly sought-after commodity with growing demand [5]. Its tuber contains Vitamin A, B, and C; and Minerals such as Potassium (K),

* Corresponding author, tel: +234-803-668-9930 
Sodium ( $\mathrm{Na})$, Chlorine $(\mathrm{Cl})$, Phosphorus (P) and Calcium (Ca). Sweet potato also contains high values of carbohydrates, vitamins, minerals, ash and protein than some vegetables, $[6,7]$. So many factors are affecting all year round supply of sweet potato in Nigeria. These factors include physical damage, pest attack, poor storage and damage during transportation. To avert some of these problems, drying is applied to preserve and protect the nutrients by removing the excess moisture that bacteria, yeasts and molds require to live and thereby providing better storage and transportation conditions. With all these advantages of drying, however, the primary disadvantage is the reduction of some sensitive nutrients by heat. The effect of drying on the nutritional quality of such heat sensitive nutrients as Ascorbic acid and thiamin has been under investigation, since the 80's [8]. Salimi et al. [9], investigated the effect of drying methods (hot air flow and microwave) on the main composition and water reabsorbing capacity of dried potato products and the results showed that the microwave maintained the value and texture of food products due to drying time reduction. Also, Falade and Solademic [10], reported that page and modified page models were appropriate for thin layer drying of 3 to $15 \mathrm{~mm}$ thick slices of sweet potato in the temperature range of $50^{\circ} \mathrm{C}$ to $80^{\circ} \mathrm{C}$. Bakal et al. [11] and Senadeera et al. [12] reported that the page model best described the drying behavior of potato.

\subsection{Ash Content in Foods}

The analysis of ash content in foods is simply the burning away of organic contents leaving inorganic minerals. This helps determine the amount and types of minerals in foods; important because the amount of minerals can determine physiochemical properties of food, as well as retard the growth of microorganisms. Therefore, ash content is a vital component in a food's nutrition, quality viability. It includes metal salts which are important for processes requiring ions such as $\mathrm{Na}^{+}$ (Sodium), $\mathrm{K}^{+}$(Potassium), $\mathrm{Ca}^{2+}$ (Calcium) and trace minerals which are required for unique molecules, such as chlorophyll and hemoglobin. Crude ash contains substances which can be absorbed as minerals or trace elements and are essential for many processes in the body [13].

\subsection{Crude Fiber}

Fiber is a type of carbohydrate that the body can't digest. Animals need this indigestible proportion of fiber in their diet to support digestion. The crude fibers also make sure that the food is better absorbed. Though most carbohydrates are broken down into sugar molecules, fiber cannot be broken down into sugar molecules and instead it passes through the body undigested.

It helps regulate the body use of sugars, helping to keep hunger and blood sugar in check. Fiber has been recommended as an important dietary requirement by the American Institute of Medicine at the dose of about $38 \mathrm{~g}$ of fiber per day for men, while women require 25 $\mathrm{g}$ per day for good living [14].

These two nutritional components of foods have not been given adequate attention by food researchers, even though they fill important gaps in nutritional status and nutrient availability of other vital elements of food.

In order to determine the best drying conditions for potato, it is important to determine and optimize the factors that significantly affect the nutritional qualities of the dried product under different drying methods. Therefore, as part of on-going investigation in the area, this study was aimed at determining the effect of microwave power and slice thickness on the fiber and ash contents of dried sweet potato slices using Fourier models and Response Surface Methodology (RSM).

\section{MATERIALS AND METHODS}

\subsection{Materials Preparation}

Sweet Potato (Ipomoea batatas) samples for the experiment were purchase from Benin in Edo State, Nigeria. Edo state belongs to South-South region and in the Niger Delta area of Federal Republic of Nigeria. The sweet potatoes were peeled using stainless steel kitchen knife, after which it was soaked in lukewarm water to avoid risk of losing their nutritional qualities in addition to reducing water that was lost after exposing the interior by peeling [15]. The soaking period of 10 to 15 minutes was for the time between sample preparation and drying experiment to block the effects of soaking or steeping which was not part of the study. The potatoes were sliced into thickness of $3 \mathrm{~mm}, 4 \mathrm{~mm}$ and $6 \mathrm{~mm}$. sampes of $140 \mathrm{~g}$ each were used in drying experiment in a microwave oven (MCE02037) with rated microwave power of $2500 \mathrm{~W}$. 


\subsection{Description of Experiment}

The drying and proximate experimental tests were carried out at Nigeria Institute for Oil-palm Research (NIFOR) Central Analytical Laboratory, Benin City. The experiment was carried out using fresh samples of sweet potato subjected to microwave oven drying at slice thickness $3 \mathrm{~mm}, 4 \mathrm{~mm}, 6 \mathrm{~mm}$ and microwave power of $90 \mathrm{~W}, 100 \mathrm{~W}, 120 \mathrm{~W}$. Preliminary experiments showed that there was no noticeable difference in the response values of slice thickness of $4 \mathrm{~mm}$ and $5 \mathrm{~mm}$. It was therefore decided to increase thickness to $6 \mathrm{~mm}$ and consequently microwave power to $120 \mathrm{~W}$.

The sample drying took place in microwave oven equipped with power control and timer facilities. The samples were weighed at 30 minutes intervals until constant weight is reached for every combination of microwave power and slice thickness. At the end of each drying run, the samples were cooled in desiccators and subsequently tested for the values of ash and fiber. Among the precautions taken to reduce experimental error was to place the hot sample cans from the oven in desiccators to cool before weighing to reduce buoyancy effect.

\subsection{Determination of Proximate Composition}

The proximate analysis was carried out according to stipulated procedure laid down for analysis of biological materials [16-19]. After each experimental run, under each designated experimental condition, the dried sample was collected for proximate analysis while values of the fiber and ash contents were observed for statistical analysis and modeling.

\subsubsection{Determination of ash content}

The ash content of the sample is the residue remaining after ignition at $550^{\circ} \mathrm{C}$ for 180 minutes to burn off all the organic matter or carbon. Two grams $(2 \mathrm{~g})$ of defatted sample was added into the ashing beaker and the weight of the beaker sample plus sample $\left(\mathrm{W}_{1}\right)$ was noted. It was Ashed for 3 hours at $550^{\circ} \mathrm{C}$ in the muffle furnace and allowed to cool in a desiccator. The Weight of the Ashing beaker and dried sample ( $\left.\mathrm{W}_{2}\right)$ was noted.

\subsubsection{Determination of crude fiber content}

Crude fibre is the organic residue left after the defatted sample has been treated with $1.25 \% \mathrm{H}_{2} \mathrm{SO}_{4}$, $1.25 \% \mathrm{NaOH}, 10 \% \mathrm{HCL}$, absolute ethanol and petroleum ether (BP $40-60^{\circ} \mathrm{C}$ ). \% Ash content is computed using equation (1).

$$
\% A s h=\left[\frac{W_{1}-W_{2}}{W_{1}-W_{0}}\right] \times \frac{100}{1}
$$

Where, $W_{0}=$ mass of Ashing beaker $(g), W_{1}=$ mass of sample + mass of Ashing beaker $(\mathrm{g})$ and $\mathrm{W}_{2}=$ mass of Ashing Beaker + Ash after ignition ( $g$ ) [13].

Two grams (2g) of defatted sample was weighed into a $250 \mathrm{ml}$ conical flask $\left(\mathrm{W}_{0}\right) .200 \mathrm{ml}$ of $1.25 \% \mathrm{H}_{2} \mathrm{SO}_{4}$ was added into the $250 \mathrm{ml}$ conical flask and allowed to boil gently on a hot plate for 30 minutes, covered with reflux tube while heating. It was filtered through an ashless filter paper $(110 \mathrm{~mm})$ stretched over a plastic funnel and rinsed with hot distilled water. As the filtrate was clear, the sample was scraped back into the conical flask with spatula. Then rinse once with $10 \% \mathrm{HCL}$, twice with absolute ethanol and thrice with petroleum ether $\left(\mathrm{BP} 40-60^{\circ} \mathrm{C}\right.$ ) and allowed to drain dry before scraping the residue into an ashing beaker. With the sample in the ashing beaker, dry in oven over night at $105^{\circ} \mathrm{C}$. Allow to cool in desiccators before weighing the sample $\left(\mathrm{W}_{1}\right)$. Then, ash for 90 minutes at $550^{\circ} \mathrm{C}$ in a muffle furnace and allow cooling in a desiccator and weighing again $\left(\mathrm{W}_{2}\right)$. The \% Crude fiber is computed using equation 2 .

$$
\% \text { Crude fiber }=\left[\frac{W_{1}-W_{2}}{W_{0}}\right] \times \frac{100}{1}
$$

Where, $W_{0}=$ mass of sample $(g), W_{1}=$ mass of Ashing beaker + residue after drying and $\mathrm{W}_{2}=$ mass of Ashing beaker + Ash after incineration [13].

\subsubsection{Determination of Moisture Content}

Moisture content determination was carried out using the American Society of Agricultural and Biological (ASABE) Standard [20]. The samples were dried in the convective air oven at $130^{\circ} \mathrm{C}$ for twelve (12) hours. It was weighed at thirty (30) minutes intervals until there were about three subsequent equal weights in a row. This is assumed to be the weight of the dry matter (DM). If $W_{0}$ is the weight of the sample can, $W_{1}$ is the weight of the can and the initial sample and $W_{3}$ the weight of the can and the dried sample (DM), the moisture content can be calculated using equation 3 .

$$
\mathrm{MC}=\left[\frac{\mathrm{W}_{3}-\mathrm{W}_{0}}{\mathrm{~W}_{3}}\right] \times \frac{100}{1}
$$

\subsection{Drying Modeling}

Matlab software was used for drying graphs plotting and curve fittings using the data obtained from the drying experiments. Fourier and exponential models were selected for their good fits. The goodness of fit was based on Root Mean Square Error (RMSE), Mean Bias Error (MBE) and Coefficient of determination $\left(R^{2}\right)$ 
values. The Matlab software toolbox was used to fit the experimental data to the two models in order to determine the drying rate constant (k). The exponential and Fourier models are shown in Equations 4 and 5 respectively.

$$
M R=A e^{-K t}
$$

$\mathrm{MR}(\mathrm{t})=\mathrm{a}_{0}+\mathrm{a}_{1} * \cos (\mathrm{t} * \mathrm{w})+\mathrm{b}_{1} * \sin \left(\mathrm{t}^{*} \mathrm{w}\right)+$ $a_{2} * \cos (2 * t * w)+b_{2} * \sin (2 * t * w)+a_{3} * \cos (3 * t * w)+$ $\mathrm{b}_{3} * \sin \left(3 * \mathrm{t}^{*} \mathrm{w}\right)+\mathrm{a}_{4} * \cos \left(4{ }^{*} \mathrm{t}^{*} \mathrm{w}\right)+\mathrm{b}_{4} * \sin \left(4 * \mathrm{t}^{*} \mathrm{w}\right)$

Where, MR is the moisture ratio of the drying material, $A$ is the pre-log factor, $k$ is the drying rate constant and $t$ is drying time. In Equation $4, a_{0}, a_{1}, \ldots b_{4}$ are model constants, $\mathrm{t}$ is drying time and $\mathrm{w}$ is weighted parameter of the model.

\subsection{Effective Moisture Diffusivity}

The effective moisture diffusivity $\left(D_{\text {eff }}\right)$ is an index of mass transfer in drying process [21]. According to Fick's law of diffusion and continuity relation, fluxchange over distance equals the rate at which the moisture concentration in the volume is decreasing with time, as demonstrated in Equations (6) and (7) $[22,23]$.

$$
\partial \mathrm{M} / \partial \mathrm{t}=-\partial \mathrm{J} / \partial \mathrm{x}
$$

or

$$
\frac{\partial M}{\partial t}=\frac{\partial}{\partial x}\left(D \frac{\partial M}{\partial x}\right)
$$

The solution to Equation 7, considering a slab of thickness 21 o takes the form of sum of series viz equation 8:

$$
M R=\frac{8}{\pi^{2}} \sum_{N=1}^{\infty} \frac{1}{(2 n-1)^{2}} \exp \quad\left(-\frac{(2 n-1)^{2} \pi^{2} D t}{4 l_{o}^{2}}\right)
$$

Where, $\%$ =half of slab thickness, $D=$ diffusion coefficient or diffusivity and $\mathrm{t}=$ time.

Hence, taking the first term of the equation yields equations 9 and 10 .

$$
\begin{aligned}
& M R=\frac{8}{\pi^{2}}\left[\frac{1}{(2 n-1)^{2}} \quad \exp \left(-\frac{(2 n-1)^{2} \pi^{2} D t}{4 l_{o}^{2}}\right)\right] \\
& M R=\frac{8}{\pi^{2}} \exp \quad\left(-\frac{\pi^{2} D t}{4 l_{o}^{2}}\right)
\end{aligned}
$$

If we set $\mathrm{A}=\frac{8}{\pi^{2}}, \mathrm{k}=\frac{\pi^{2} D t}{4 l_{0}^{2}}, \mathrm{MR}=\frac{M-M_{e}}{M_{o}-M_{e}}=$ and $\mathrm{n}=1$, Equation9 can be written as (11):

$$
\mathrm{MR}=\frac{M-M_{e}}{M_{o}-M_{e}}=A \cdot \exp (-k t)
$$

Comparing equations (9) and (10) and setting $K=$ $\frac{\pi^{2} D t}{4 l_{0}^{2}}$, can be made the subject of the equation to yield Equation 12.

$$
D=\frac{4 K l_{0}^{2}}{t \pi^{2}}
$$

To use equations $8-11$ for this study

$$
, \mathrm{l}_{\mathrm{o}}=\text { half thickness of the potato slice }
$$

\subsection{Drying Models}

The exponential drying model equations were developed using experimental data in order to determine the drying parameters such as drying constants $(k)$. The goodness of fit was predicated on R-square, RSME, MBE at 95\% confidence level. The Fourier models were validated by comparing experimental data with the predicted data. The models showed good fits for data and adequately described the drying kinetics of sweet potato slices as compared to exponential equations considering the better values of MBE, R-square, RMSE at confidence bound of $95 \%$ [24].

\subsection{Error Analysis}

The coefficient of determination $\left(R^{2}\right)$ was primary criterion for selecting the most suitable equation to describe the microwave drying curves of potato slices. This can be used to test the relation between measured and estimated values and can be calculated from the equation 13 [24]:

$R^{2}=\frac{\sum_{i=1}^{N}\left(X_{\exp (j)}-X_{\exp (\text { mean }) j}\right)^{2}-\left(X_{\text {pre }(j)}-X_{\exp (j)}\right)^{2}}{\sum_{i=1}^{N}\left(X_{\exp (j)}-X_{\exp (\text { mean }) j}\right)^{2}}$

where $X_{\text {exp, } i}$ stands for the experimental value found in any measurement, $X_{\text {pre }, i}$ is the predicted value for this measurement and $N$ is the total number of observations. The higher the value of $\mathrm{R}^{2}$ the better the model prediction.

Mean Bias Error (MBE) provides information on the performance of the correlations by allowing a comparison of the actual deviation between predicted and measured values term by term. The ideal value of $M B E$ is "zero". The expression for MBE is given in equation 14 [24].

$$
M B E=\frac{1}{N} \sum_{i=1}^{N}\left(X_{\text {pred }, i}-X_{\text {exp }, i}\right)
$$

Where, $\mathrm{n}_{\mathrm{i}}$ is called number of constants.

The root mean square error (RMSE) may be computed from the following equation 15 , which provides information on the model's performance. The lower the value of RMSE the better the model.

$$
R M S E=\frac{\sqrt{\left[\sum_{i=1}^{N}\left(X_{\text {exp. } . j}\right)-\sum_{i=1}^{N}\left(X_{\text {pre. }}\right)\right]^{2}}}{N}
$$

\subsection{Effects of Microwave Drying on the Ash and Fiber}

Analysis of variance (ANOVA) was performed on the data collected from the experimental investigation 
using RSM (Two-factor general factorial design) at Pvalue $<0.05$. The software was also used to determine the optimal combination of microwave power and slice thickness required for drying of the potato slices under microwave drying using ash and fiber contents as the quality parameters yard stick. Hence optimized predictive equations were developed in terms of the process variables (microwave power and slice thickness) and responses (ash and fiber).

\section{RESULTS AND DISCUSSION}

\subsection{Drying Curve Fitting}

Drying curves of moisture ratio (MR) against time (t) for different drying conditions were plotted and presented in Figures 1 to 3 . The drying characteristics of the slices were described in the plot of moisture ratio (MR) against drying time ( $t$ ). The drying process took place in falling rate period, which can be observed in the graphs.

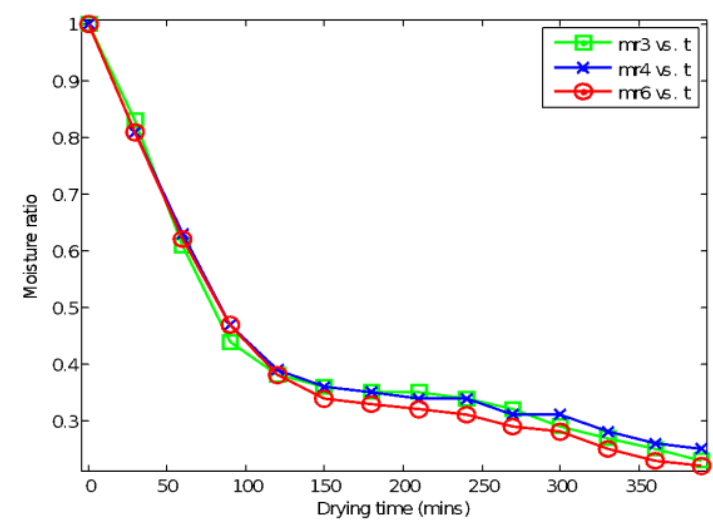

Fig.1: Effect of thickness on microwave drying curve of sweet potato at $90 \mathrm{~W}$

Where, $\mathrm{mr} 3, \mathrm{mr} 4$ and $\mathrm{mr} 6$ are moisture ratios (MR) for slice thickness of $3 \mathrm{~mm}, 4 \mathrm{~mm}$ and $6 \mathrm{~mm}$ respectively.

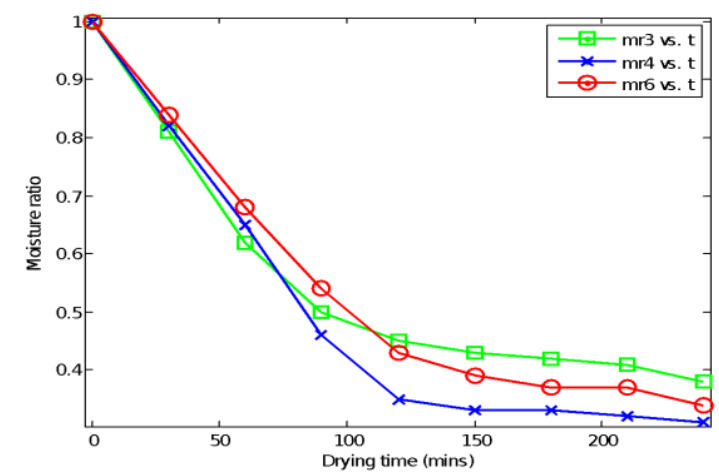

Fig.2: Effect of thickness on microwave drying curve of sweet potato at $100 \mathrm{~W}$

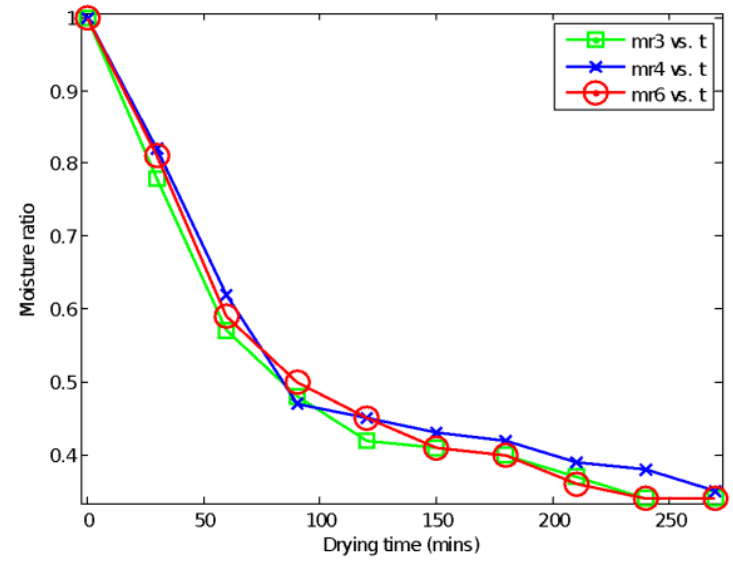

Fig.3: Effect of thickness on microwave drying curve of sweet potato at $120 \mathrm{~W}$

This can be explained to be as a result of faster surface water removal compared with the slower outward diffusion rate from the interior to the surface. This phenomenon has been reported for agricultural and porous materials [25].

The range of values of Fourier model fit parameters were obtained as follows: MBE from 0.0001042 to 0.00002941 , R-square from 0.9987 to 1 , RMSE from 0.01062 to 0.007249 . Aishi and Feiyan [26], applied logarithm model to the same product and reported as follows:

R-square 0.9617 to 0.9997 and RMSE 0.011894 to 0.007530 .

The developed models and their corresponding fit parameters are presented on Table 1 while the corresponding constants are presented in Table 2 for the general Fourier model given in Equation 2.

\subsection{Effective Moisture Diffusivity}

The result of the investigation showed that effective moisture diffusivity of Sweet potato undergoing microwave drying varied from $1.5279 \times 10^{-5}$ to $4.6562 \times 10^{-5} \frac{\mathrm{m}^{2}}{\mathrm{~s}}$. Rufus [26] reported effective moisture diffusivity of sweet potato as ranging from $2.962 \times 10^{-10}$ to $4.694 \times 10^{-10} \mathrm{~m}^{2} / \mathrm{s}$. These values are within the range of values obtained in this study. The variation could be due to species used and approximation.

\subsection{Effect of Drying on Proximate Composition}

The experimental design matrix and the corresponding values of the response variables are presented in Table 3. 
Table 1: Fourier models for drying at different microwave power and slice thickness

\begin{tabular}{|c|c|c|c|c|c|}
\hline Power(w) & $\mathrm{ST}(\mathrm{mm})$ & Model expression & MBE & $\mathrm{R}^{2}$ & RMSE \\
\hline 90 & 3 & $a_{0}+a_{1} * \cos (t * W)+\ldots+b_{4} * \sin (4 * t * W)$ & $7.08 \mathrm{E}-05$ & 0.9999 & 0.004207 \\
\hline 100 & 3 & $\mathrm{a}_{0}+\mathrm{a}_{1} * \cos (\mathrm{t} * \mathrm{~W})+\ldots+\mathrm{b}_{2} * \sin (2 * \mathrm{t} * \mathrm{~W})$ & 0.000113 & 0.9997 & 0.006145 \\
\hline 120 & 3 & $a_{0}+a_{1} * \cos (t * w)+\ldots+b_{3} * \sin (3 * t * w)$ & 0.000258 & 0.9994 & 0.01135 \\
\hline 90 & 4 & $a_{0}+a_{1} * \cos (t * w)+\ldots+b_{5} * \sin (5 * t * W)$ & 0.000225 & 0.9997 & 0.01062 \\
\hline 100 & 4 & $a_{0}+a_{1} * \cos (t * W)+\ldots+b_{2} * \sin (2 * t * W)$ & 0.000645 & 0.9988 & 0.01466 \\
\hline 20 & 4 & $a_{0}+a_{1} * \cos (t * W)+\ldots+b_{3} * \sin (3 * t * W)$ & 0.000311 & 0.9993 & 0.01248 \\
\hline 90 & 6 & $a_{0}+a_{1} * \cos (t * w)+\ldots+b_{5} * \sin (5 * t * W)$ & $2.94 \mathrm{E}-05$ & 1 & 3.84E-03 \\
\hline 100 & 6 & $a_{0}+a_{1} * \cos (t * W)+\ldots+b_{2} * \sin (2 * t * W)$ & 0.000104 & 0.9998 & 0.005893 \\
\hline 120 & 6 & $a_{0}+a_{1} * \cos (t * W)+\ldots+b_{3} * \sin (3 * t * W)$ & 0.000573 & 0.9987 & 0.01692 \\
\hline
\end{tabular}

Table 2: Table of constants of the general Furrier equation at various drying conditions in the microwave (Mw) oven

\begin{tabular}{|c|c|c|c|c|c|c|c|c|c|c|c|c|c|}
\hline Factors & \multicolumn{13}{|c|}{ Mode constants } \\
\hline $\mathrm{MP}(\mathrm{W})$ & St (mm) & $\mathrm{a}_{0}$ & $a_{1}$ & $\mathrm{~b}_{1}$ & $\mathrm{a}_{2}$ & $b_{2}$ & $a_{3}$ & $b_{3}$ & $a_{4}$ & $\mathrm{~b}_{4}$ & $a_{5}$ & $b_{5}$ & w \\
\hline 90 & 3 & 0.4665 & 0.2777 & 0.02658 & 0.1779 & -.05151 & 0.06528 & -0.0365 & 0.012 & -.01599 & 0 & 0 & 0.01136 \\
\hline 100 & 3 & 0.6799 & 0.3118 & -0.2294 & 0.0095 & -0.1248 & 0 & 0 & 0 & 0 & 0 & 0 & 0.01264 \\
\hline 120 & 3 & 0.5956 & 0.3168 & 0.0843 & 0.0940 & 0.1191 & -0.0054 & 0.0291 & 0 & 0 & 0 & 0 & -0.0152 \\
\hline 90 & 4 & $5.29 \mathrm{E} 7$ & $-8.37 \mathrm{E} 7$ & $2.82 \mathrm{E} 7$ & 4.04E7 & $-0.08 \mathrm{E} 7$ & $-1.08 \mathrm{E} 7$ & 1.60E7 & 1.15E 6 & $-.195 \mathrm{E} 6$ & 2.61E4 & 4.43E5 & -0.0015 \\
\hline 100 & 4 & 0.5677 & 0.3450 & -01282 & 0.0833 & -.0928 & 0 & 0 & 0 & 0 & 0 & 0 & 0.0129 \\
\hline 120 & 4 & 0.4874 & 0.2810 & 0.0859 & 0.1982 & -.0829 & 0.0334 & -0.0649 & 0 & 0 & 0 & 0 & 0.0125 \\
\hline 90 & 6 & $-3.74 \mathrm{E} 9$ & $6.12 \mathrm{E} 9$ & 1.19E9 & $-3.32 \mathrm{E} 9$ & $-.34 \mathrm{E} 9$ & 1.13E9 & 7.37E8 & $-.17 \mathrm{E} 8$ & $-.11 \mathrm{E} 8$ & $1.74 \mathrm{E} 7$ & $2.51 \mathrm{E} 7$ & 0.001 \\
\hline 100 & 6 & -26.53 & 35.02 & 13.43 & -7.49 & -7.37 & 0 & 0 & 0 & 0 & 0 & 0 & 0.0045 \\
\hline 120 & 6 & $-3.50 \mathrm{E} 10$ & $5.25 \mathrm{E} 10$ & 1.42E9 & $-2.1 \mathrm{E} 10$ & $-1.14 \mathrm{E} 9$ & $3.49 \mathrm{Eg}$ & 2.84E8 & 0 & 0 & 0 & 0 & 0.0002 \\
\hline
\end{tabular}

Where, $\mathrm{mr}=$ moisture ratio; $\mathrm{Mw}$. $\mathrm{P}=$ Microwave power; $\mathrm{St}=$ Slice thickness; $\mathrm{t}=$ drying time; $\mathrm{w}=\mathrm{weighted}$ parameter

Table 3: Experimental layout showing Mean values of responses variables (fiber\% and ash\%) at design points

\begin{tabular}{lllll}
\hline Sample treatment & Microwave Power $(\mathrm{W})$ & Slice thickness $(\mathrm{mm})$ & Fibre(\%) & Ash(\%) \\
\hline \multirow{5}{*}{ Microwave drying } & 90 & 3 & 2 & 4 \\
& 100 & 3 & 1 & 2.8 \\
& 120 & 3 & 1.5 & 2 \\
& 90 & 4 & 2.4 & 4.1 \\
& 100 & 4 & 2 & 3.6 \\
& 120 & 4 & 1 & 2.4 \\
& 90 & 6 & 2.5 & 4.3 \\
& 100 & 6 & 2 & 3.4 \\
& 120 & 6 & 1.5 & 2.9 \\
\hline
\end{tabular}

The result of proximate composition of sweet potato was analyzed at various conditions of the drying experiments in order to determine the effects of the drying conditions on the per cent availability of ash and fiber expressed in terms of the initial fresh charge after microwave drying. From the experimental results, it can be observed that sweet potato at microwave power of $90 \mathrm{~W}$ and thickness of $6 \mathrm{~mm}$ had the highest value of fiber (2.50\%) and Ash (4.30\%) as a percentage of the initial fresh charge which is an indication that the lower the microwave power and the higher the slice thickness, the more the $\%$ fiber 
and \% ash retention. This trend agrees with Torgrul, [27] and Negi and Roy [28], who reported on the effect of drying rate on the flavor and nutritional value retention in food crops.

\subsection{Analysis of Variance}

The Analysis of Variance (ANOVA) was conducted to determine the levels of significance of individual factors and their interactions on the response variables (\%ash and \%fiber). The results are presented in Tables 4 and 5.

The model F-values show the significance of the model within the confidence bound of $95 \%$. From
Tables 4 and 5 the F-values show that the models were significant for both ash and fiber.

The lack of fit measures points of data that are not included in the experimental plot. Tables 4 and 5 show that the models have significant lack of fit. The p-value (probability of error value), indicates the suitability of the models and predictability of the response variables, stating whether the model fits well or not. The ANOVA (Tables 4 and 5 ) show that the models fit well because $p$-value less than 0.05 indicates that model terms are significant while a value greater than 0.05 indicates non significance.

Table 4. ANOVA for Response Surface Linear Model for Fibre Content

\begin{tabular}{|c|c|c|c|c|c|c|}
\hline Source & $\begin{array}{l}\text { Sum of } \\
\text { Squares }\end{array}$ & DF & $\begin{array}{l}\text { Mean } \\
\text { Square }\end{array}$ & $\begin{array}{l}\mathrm{F} \\
\text { Value }\end{array}$ & Prob > F & \\
\hline Model & 5.99 & 5 & 1.2 & 10.45 & $<0.0002$ & Significant \\
\hline A-power & 4.62 & 1 & 4.64 & 40.49 & $<0.0002$ & \\
\hline B-thickness & 1.00 & 1 & 1.001 & 8.74 & 0.0081 & \\
\hline$A^{2}$ & 0.64 & 1 & 0.64 & 5.61 & 0.0286 & \\
\hline$B^{2}$ & 0.16 & 1 & 0.16 & 1.4 & 0.2510 & \\
\hline$A B$ & 0.15 & 1 & 0.15 & 1.34 & 0.2615 & \\
\hline Residual & 2.18 & 19 & 0.11 & & & \\
\hline Lack of Fit & 2.64 & 6 & 0.44 & 3.53 & 0.0173 & Significant \\
\hline Pure Error & 2.24 & 18 & 0.12 & & & \\
\hline Cor Total & 9.91 & 26 & & & & \\
\hline R-Square & 0.7333 & & & & & \\
\hline Adj R-Square & 0.6631 & & & & & \\
\hline Adeq. Precision & 11.516 & & & & & \\
\hline CV & 19.043 & & & & & \\
\hline
\end{tabular}

Table 5. ANOVA for Response Surface Quadratic Model for Ash Content.

\begin{tabular}{lllllll}
\hline Source & $\begin{array}{l}\text { Sum of } \\
\text { squares }\end{array}$ & df & $\begin{array}{l}\text { Mean } \\
\text { squares }\end{array}$ & F Value & Prob $>$ F & \\
\hline Model & 15.01 & 5 & 3 & 27.66 & $<0.0001$ & Significant \\
A & 12.3 & 1 & 12.3 & 113.36 & $<0.0001$ & \\
B & 1.77 & 1 & 1.77 & 16.3 & 0.0006 & \\
A $^{2}$ & 0.52 & 1 & 0.52 & 4.8 & 0.0399 & \\
B $^{2}$ & 0.32 & 1 & 0.32 & 2.9 & 0.1032 & \\
AB & 0.27 & 1 & 0.27 & 2.53 & 0.1268 & \\
Residual & 2.28 & 19 & 0.028 & & & Not significant \\
Lack of Fit & 0.4 & 3 & 0.13 & 1.27 & 0.3134 & \\
Pure Error & 1.88 & 18 & 0.1 & & & \\
Cor Total & 17.29 & 26 & & & & \\
R-Square & 0.96555 & & & & & \\
Adj. R-Squre & 0.7579 & & & & & \\
Adeq. Precision & 17.3675 & & & & & \\
CV & 5.13 & & & & & \\
\hline
\end{tabular}


Coefficient of Variation (CV) is the standard deviation expressed as a percentage of the mean. A CV values less than $10 \%$ indicates the model has a good precision, and table 4 shows a reasonable precision being (19.043 for \%fiber) not far from $10 \%$ while table 5 ( 1.53 for \%ash) show very good precision. Coefficient of determination ( $R$-squared or $R^{2}$ ), measures the amount of variation around the mean explained by a model [29]. The higher the $R^{2}$ the better the prediction of the response variables. Table 4 and 5 show good coefficient of determination of 0.7333 and 0.9655 for fiber and ash respectively, which are high enough to conclude that the models can give good prediction.

A pred. $R^{2}$ determines how the regression model can make prediction and provide a good fit. The "Pred RSquared" of Tables 4 and 5 are in reasonable agreement with the "Adj R-Squared". Adequate precision compares the range of predicted values at the design points to the average prediction error. Adequate precision value greater than 4 is considered adequate and 1.24 indicate an inadequate signal. Tables 4 and 5 indicate an adequate signal.

Optimization and functional dependencies among the factors in this investigation were studied using regression method. The optimized models relating microwave power $(P)$ and slice thickness $(T)$ with fiber and ash contents of the dried potatoes are presented in Equations 16 and 17. The model expressions are quadratic and are found to be significant in the ANOVA tables (Tables 4 and 5 )

$$
\begin{aligned}
\text { fiber }(\%)=18.89 & -0.362 P+1.418 T \\
& +1.667(e-3) P^{2}-0.083 T^{2} \\
& -4.847(e-3) P T
\end{aligned}
$$

The coefficient of determination $\left(R^{2}\right)$ is 0.7333 .

$$
\begin{aligned}
\operatorname{ash}(\%)=25.29 & -0.399 P+0.58 T+1.50(e-3) P^{2} \\
& -0.117 T^{2}+6.48(e-3) P T
\end{aligned}
$$

The coefficient of determination $\left(R^{2}\right)$ is 0.9655 .

\subsection{The 3D Response Surface Plots}

The graphical presentation of the interaction effects of microwave power and thickness on ash and fiber are shown in figures 4 and 5. The 3-D plots represent the interactive plots of two factors at a time with each of the response variables. They show the nature of the governing equations/models (straight line, quadratic or cubic etc.). From the plots, both responses (ash and fiber) vary with the treatments (microwave power and slight thickness). However, while fiber is more of a linear decreasing function sloping from left to right, ash is more quadratic facing upward. Ash plot represents a quadratic (minimizing) function of the independent variables, which agrees with the expected drying conditions.

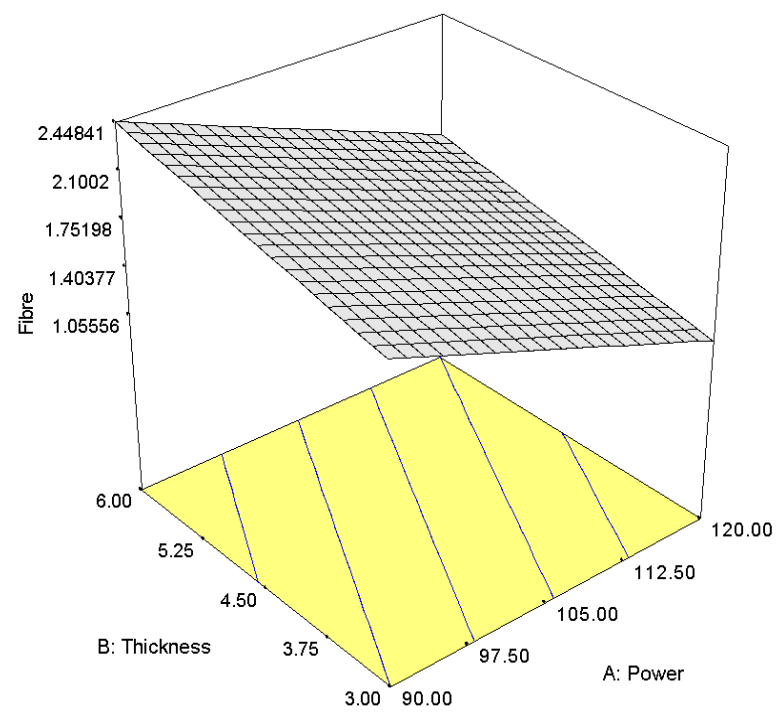

Figure 4: 3-D surface plot of Thickness vs Power for fiber content

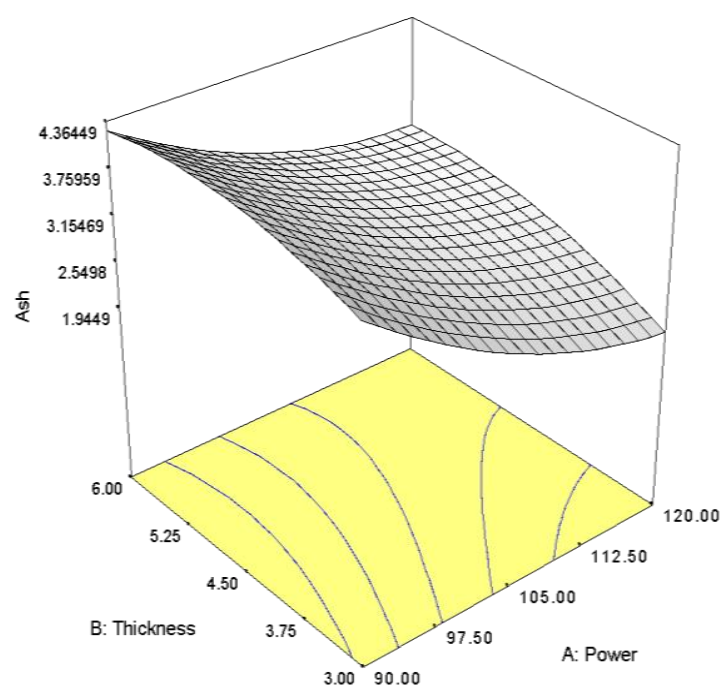

Figure 5: 3-D surface plot of Thickness vs Power for ash content

\subsection{The Models' Calibration and Validation}

The software has an inbuilt capacity to perform both calibration and validations and give the output in graphs of predicted against experimental data. If all the points lie on the trend line, the interpretation is that the model prediction is perfect but is still good when scattered closely round the trend line. From figures 6 and 7, it can be deducted that the models can predict the $\%$ ash and $\%$ fiber contents with a good degree of accurately. 


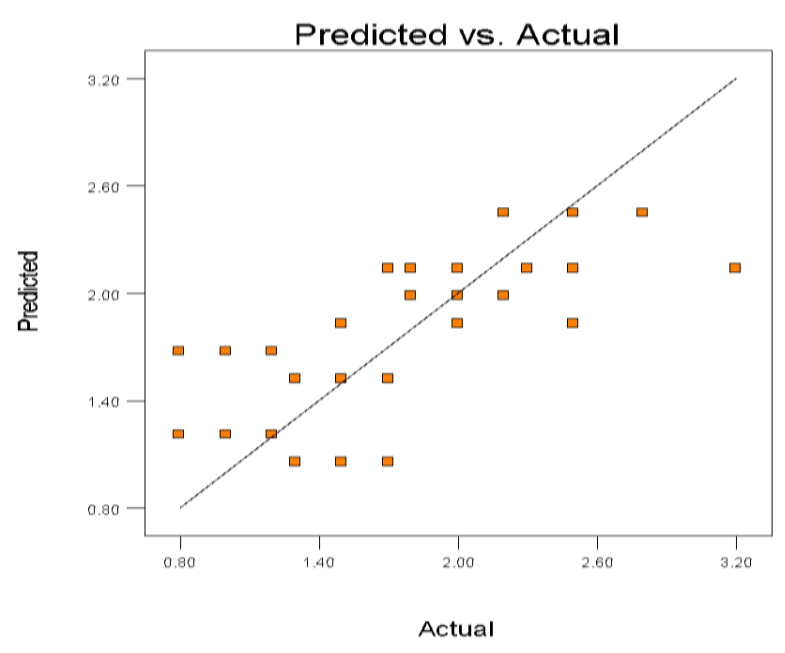

Figure 6: The plot of predicted vs actual contents of fiber

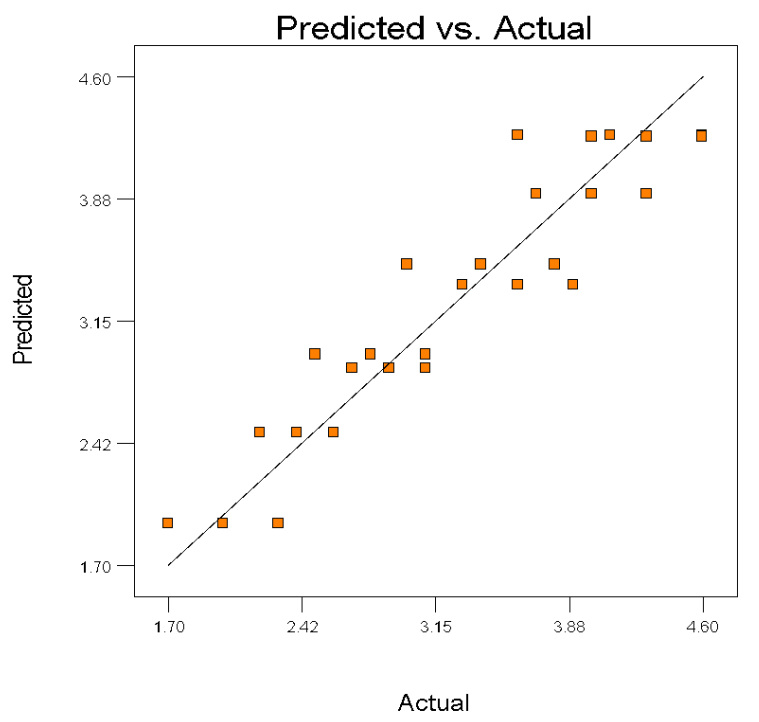

Figure 7: The plot of predicted vs actual contents of Ash

\section{CONCLUSIONS}

The investigation of the microwave drying characteristics of sweet potato slices and the effects of microwave power, and slice thickness on the fiber and ash retention were studied. It was observed that drying of sweet potato took place in the falling rate period of the drying process.

The Fourier model equations adequately fitted the microwave drying data within the ranges of power and slice thickness studied.

Optimal equations for predicting drying characteristics of the potato slices in microwave oven were developed and were used to predict the moisture ratio at various drying conditions studied. Good predictions were observed with the following ranges of values of fit parameters: coefficient of determination $\left(R^{2}\right)$ ranging from 0.9993 to $1, \mathrm{MBE}$ from 0.00002941 to 0.0005148 , RMSE from 0.003806 to 0.01062 .

Analysis of Variance (ANOVA) was used to determine the level of significance of the experimental variables as well as model equations developed for prediction of ash and fiber contents at different drying conditions. The optimized equations were significant and the effects of single and interactions were also significant at at $p<0.05$. It can therefore be inferred that the process variables of slice thickness, microwave power and their interactions have significant effect on per cent ash and fiber contents of the samples as measured and expressed in terms of fresh samples. At the microwave power of $90 \mathrm{~W}$ and thickness of $4 \mathrm{~mm}$ the value of Fiber and Ash retained in the dried sweet potato samples were optimum.

\section{REFERENCES}

[1.] Raquel. P.F. Guine (2018). The drying of Foods and its Effect on the Physical-Chemical, Sensorial and Nutritional Properties. International Journal of Food Engineering. Vol. 4 (2). Pp. 93-100.

[2.] Zieinska M and Michalska A (2016). Microwave assisited drying of Blueberry (Vaccinium corymbosum. L) fruits: Drying Kinentics, Polyphenols, anthocyanins, antioxidants capacity. Vol. 212 PP. 671-680.

[3.] Food Agriculture Organisation(FAO), (1987). Roots and tubers: their role in food security courier.

\section{[4.] FAOSTAT, (2010). http://faostat.fao.org}

[5.] Singh, R.H., Seepersad, G. and Rankine L.B. (2006). Executive summary. The global market for sweet potato: Sources of supply and competitiveness for the CARICOM industry-The CARICOM

[6.] Onwueme, I.C. and Sinha, T.D. (1991). "The tropical tuber crops". John wiley and Sons Publishing Chinchester New York.

[7.] Shih, R.H., Yeh, C.T. and Yen, G.G. (2007). Anthocyanins induce the activation of phase II enzymes through the antioxidant response element pathway against oxidative stressinduce Apoptosis. Journal of Agricultural and Food Chemistry, 55:9427-9435.

[8.] Fennema, O. (1982). Effect of processing on nutritive value of food: freezing, In Handbook of nutritive value of processed food, ed, by 
Rechugi, M. CRC Press, Boca Ration, Florida. Pp 31-43.

[9.] Salimi, A., Maghodlo, Y., Mirzaei, H.A. and Kashaninejad, M. (2009). Effect of drier type, cultivar, product and water temperature on major components and rehydration ratio of dried potato products. Journal of Agricultural Science and Natural Resource pp16(1),1-13

[10.] Falade, K.O and Solademic, O.J. (2010). Modeling $f$ Air Dying of Fresh and Blanched Sweet Potato Slices. International Journal of Food Science and Technoogy, 45(2): 278-284.

[11.] Bakal, S.B.,Sharma, G.P., Sonawane, S.P. and Verma, R.C. (2011). Kinetics of Potato drying using fluidized bed dryer. Doi: 10.1007/S13197-011-0328-X

[12.] Senadeera, W., Bhandari, B.R., Young, G. and Wijesinghe, B. (2003). Influence of shapes of selected vegetable materials on drying kinetics during fluidized bed drying. Journal of Food Engineering, 58:277-283.

[13.] Kerri-Ann (2016). Kerri-Ann Jennings (2016). 16 Easy ways to Eat Moor Fiber: Healthline. Nutrition, July 27, 2016.

[14.] Manaa, S., Younsi, M. and Moummi, N. (2013). Study of methods for drying dates; Review the traditional drying methods in the region of Touat wilaya of Adar-Algeria. TerraGreen 13 international conference 2013- Advancement in Renewable Energy and Clean Environment.

[15.]AOAC (1990). Official methods of analysis (12th ed.), Association of Official Analytical Chemists. Washington, DC.

[16.]Bakare (1985). Methods of biochemical analysis of plant tissue. (Unpublished document) Agronomy Department, University of Ibadan

[17.]Tell, D.A. and Hagarty, M. (1984). Soil and plant Analysis. IITA.

[18.] Onyeonwu, R.O. (2000). Macgill environmental research laboratory limited (MERLL). Analysis manual pg. 31.

[19.] Sacilik, K. (2007). Effect of drying methods on thin-layer drying chacteristics of hull-less seed pumpkin (Cucurbita pepo L.). Journal of Food engineering, 73:23-30.

[20.] ASABE (1993). American Society of Agricultural and Biological Engineers (ASABE) Standard Moisture Measurement, S.358.2 (Dec 93).

[21.] Babalis, S.J. and Belessiotis, V.G. (2004). Influence of drying condition on the drying constants and moisture diffusivity during the thin-layer of figs. Journal of Food Engineering, $65,449-458$.

[22.] Chayjan, R.A., Salari, K., Barikloo, H. (2012). Modeling moisture diffusivity of pomegranate seed cultivars under fixed semi fluidized bed using mathematical and neutral network methods. Acta Scientiarum Polonorum., Technologia Alimentia. 11(2):131-148.

[23.]Pathare, P.B. and Sharma, G.P. (2006). Effective Moisture Diffussivity of Onion Slices Undergoing Infra-Red Cnvective Drying. Biosystems.93: 285-291.

[24.] Montgomery D.C, Runger G.C, and Humble G.C. (2011). Engineering Statistics. Fifth Edition. John Wiley \& Sons, Inc, Hoboken NJ. http:www.wiley.com/go/permissions.

[25.] Aishi, Z. and Feiyan, J. (2014). Modeling of mass transfer performance of hot air drying of sweet potato (Ipomoea batatas) slice. Chemical and Chemical Engineering Quarterly 20(2):171-187.

[26.] Togrul, H. (2006). Suitable drying model for infrared drying of carrot. Journal of Food Engineering. 77:610-619

[27.] Negi, P.S. and Roy, S.K. (2000). Effect of low cost storage and packaging on quality and nutritive value of fresh and dehydrated carrots. Journal of science Food and Agricultural, 80(15):2169-2175

[28.] Shrivastava, A., Sandagar, P., Baja, I. and Singhal, R. (2008). Media optimization for the production of U-linolenic acid by cunninghamella echinulata varielegans MTCC 522 using response surface methodology. International Journal of Food Engineering, 4(2):1-32. 